\title{
Effects of chronic illness on intellectual development
}

\author{
A comparison of normal children with those treated for childhood leukaemia \\ and solid tumours
}

CHRISTINE EISER

Academic Department of Child Psychiatry, The Hospital for Sick Children, London

SUMMARY 40 children who had been treated for acute lymphoblastic leukaemia by irradiation to the central nervous system and by chemotherapy were assessed, using general psychological measures. These children were compared with a group of normal children of similar ages and backgrounds, and with a group of 16 patients treated for solid tumours. The group of 16 patients with solid tumours was also compared with a normal control group and there were no differences between the scores for IQ, reading, memory, and learning. Children with leukaemia had lower scores then normal children for all these tasks. In young leukaemic children (those diagnosed when aged under 5 years) differences were significantly greater compared with controls. There were no effects of age at diagnosis on the scores made by children with solid tumours compared with normal children. These results implicate the role of central nervous system irradiation in reducing intellectual development in children, especially in young children, treated for leukaemia.

Any kind of chronic illness in childhood can be expected to affect the child's social adjustment, and this in turn, may be reflected in his behaviour and success at school. The illness may lead to extended absences and will therefore interrupt the continuity of lessons and affect the stability of peer relationships. In some cases, differences in appearance between the sick and the normal child may exaggerate any feelings of isolation. Despite these disadvantages, it has not been reported that sick children are measurably inferior to healthy ones in terms of intelligence levels or academic achievements. Indeed, in some cases, degrees of excellence may result from the very occurrence of the illness. ${ }^{1}$ According to Burton, ${ }^{2}$ children with cystic fibrosis who recognise their inferiority in physique and their inability to compete with others in athletic pursuits, may instead develop linguistic and communicative skills. In most cases however, a long illness in childhood is not associated with such a positive outcome. Nevertheless, many workers have reported that intelligence levels of sick children are comparable with those of normal ones. This applies, for example, to children with cystic fibrosis, ${ }^{3}$ or diabetes, ${ }^{4}$ although the latter study concluded that children diagnosed before 5 years of age were of somewhat lower ability than their siblings. One common finding is that despite a normal distribution of intelligence among sick children, attainments fall short of their potential. Such findings have been reported for a group of haemophiliacs by $\mathrm{Olch}^{5}$ and for a group of physically disabled high school students by Allen. ${ }^{6}$

Certainly there is no reason to suppose that chronic illness can affect a child's intelligence level. However, the nature and severity of the disease are only two of the influences on the child's development. One possible explanation for these findings is that changes in adult-child interaction reduce the sick child's self-esteem and lower his expectations. There have been few attempts to describe qualitative changes in parent-child interaction of teaching style as a function of illness. and the two studies that were carried out ${ }^{7-8}$ concluded that child rearing remained essentially unchanged despite a child's illness. However, both relied on parental interviews, and observations on parent-child, or teacher-child interaction, were not made.

As with other groups of sick children, those with leukaemia are unquestionably at a disadvantage at school. The distribution of intelligence levels of such children is especially interesting as the medical treatment required to control the disease may affect the child's pattern of behaviour and his intellectual 
ability. Most children with leukaemia in the UK are now treated according to one of the standard protocols described by the Medical Research Council. These treatments use a combination of chemotherapy and prophylactic central nervous system (CNS) irradiation. Usually a total of $2400 \mathrm{rad}$ is given in 15 or 18 fractions to the whole brain. Such treatment may affect brain development, as described in some recent reports of identifiable structural changes after treatment. For example, PeylanRamu, ${ }^{9}$ using computerised tomography (CT) scans, found that $25 \%$ of patients had some degree of cerebral atrophy; McIntosh et al. ${ }^{10}$ reported that $6 \%$ of patients suffered from necrosis of white matter and axonal damage; and Price and Jamieson ${ }^{11}$ suggested that the likelihood of this type of damage increased with cumulative doses of methotrexate. Despite the incidence of structural changes of this kind, early reports suggested that these did not affect intellectual ability. ${ }^{12-13}$ Other workers have not always been able to support these early findings, and changes in personality and behaviour have been reported, ${ }^{11}$ as have other abnormal neurological signs. ${ }^{14}$ Intellectual level in such children appears to be slightly lower than in normal children, ${ }^{15}$ particularly if the child is treated before he is 5 -years old.

This study was undertaken to evaluate further the role of chronic illness and CNS irradiation on intellectual development. In order to do this, leukaemic children were compared with a group of normal healthy children of similar ages and social backgrounds. As any differences between these groups might have been due to disease or treatment factors, a second group of children was also assessed. These children were chosen because they had suffered from an illness of comparable severity. In fact, they were a fairly heterogeneous group of patients with solid tumours but they, too, had coped with an illness of a similar life-threatening nature and had needed chemotherapy. They had undergone irradiation to some part of the body but, unlike the leukaemic patients, it had been to some part other than the CNS. Any differences between these groups-for instance if the patients with tumours were to score higher than the leukaemic patientsmight reasonably be attributed to the use of CNS irradiation.

A child's psychological vulnerability to any potentially adverse influence depends on many factors, and his level of development is probably the most important of these. Within the group of children treated for leukaemia therefore, we may well find differences in performance as a function of the child's age at the beginning of treatment. It is known however, that hospitalisation is associated with deviant behavioural patterns more often in young children than in older ones. ${ }^{16}$ Any hypothesis that CNS irradiation is more damaging to the younger child would therefore need to show that younger patients with leukaemia functioned psychologically less well than older patients with leukaemia, and that no comparable age effects could be found in other groups of chronically sick children.

\section{Patients and methods}

There were two groups of patients: $\mathbf{4 0}$ children who had been treated for acute lymphoblastic leukaemia and 16 who had been treated for various solid tumours. At the time of the assessment all the children were well and in remission; they had been off treatment for between 3 months and 5 years.

Patients with acute lymphoblastic leukaemia had been treated by one of the following Medical Research Council trials ( 2 children on PACS, 1 child on UK ALL I, 12 children on UK ALL II, 7 on UK ALL III, 2 on UK ALL IV, and 16 on UK ALL V). All but one child had received cranial irradiation to a total dose of 2400 rad simultaneously with intrathecal methotrexate. Maintenance therapy had continued for 2 or 3 years. These children had been aged between 18 and 142 months (mean 59) at diagnosis, and they were between 70 and 193 months (mean 115) at assessment. There were 19 boys and 21 girls in the group. Among the solid tumours, 8 had been treated for Wilms's tumours, 4 for neuroblastomas, 2 for sarcomas, and 2 for bone granulomas. These patients had been aged between 2 and 80 months (mean 47) at diagnosis, and were between 77 and 123 months (mean 106) at assessment. There were 8 boys and 8 girls in this group. In addition, there were two groups of healthy children who had no history of serious illness. They were drawn from 10 schools in the Greater London area. These children were chosen to match the patients for the following criteria: age ( \pm 3 months), sex, social class (in terms of father's occupation), one- or two-parent family.

All patients were assessed while making routine hospital check-ups. The test battery lasted approximately an hour, and included general measures of intellect and achievement, and more specific measures of memory and learning ability. All patients were assessed using a shortened form of the WISC-R. The subtests were chosen so that they covered the 3 major components of ability identified by Kaufman. ${ }^{17}$ These included two tests of verbal comprehension (similarities and vocabulary), two of perceptual organisation (block design and object assembly), and two of freedom from distractibility (digit span and coding). Reading was assessed using the Burt test.

In addition to these standardised tests of ability, 
some unstandardised tests of learning and memory were used. Learning ability was assessed using the paired-associate task described in the Wechsler adult memory scale. ${ }^{18} \mathrm{~A}$ list of 10 word pairs was read to the child, 6 were relatively easy associations (baby-cries), and 4 were hard (school-groceries). Immediately after looking at the list, the child was given each word and asked for its associate. Three trials were given.

Visual memory was assessed in two ways. Memory for common objects was tested using the technique described by Williams. ${ }^{19}$ The child was shown 9 drawings of common objects for 10 seconds. After a short interval, he was asked to recall the objects (unaided recall). For items that were not recalled, a prompt was given (aided recall). Finally, pictures of 18 objects were shown to the child and he was asked to identify the ones shown previously (recognition).

Memory for abstract material was tested using a task from the Wechsler adult memory scale. A geometric design was shown the child for 10 seconds and then he was asked to draw the design. In this manner 3 designs were shown.

Each school was asked about the child's attainments, attendance record, and behaviour. The Rutter Teacher Behaviour Questionnaire was used to determine the incidence of behavioural problems.

\section{Results}

The scores obtained by each child in the subtests of the WISC-R were converted to age-related standardised forms. The subtests were then combined to give the following measures: (1) verbal scale IQ consisting of vocabulary, similarities, and digit span subtests; (2) performance scale IQ consisting of block design, object assembly, and coding subtests; (3) full-scale IQ, the weighted scores derived from the verbal and performance scale IQs.

Three other measures were derived for each child; these reflected the three main factors of ability of the Wechsler scale:17 (1) verbal comprehension (vocabulary and similarities subtests), (2) perceptual organisation (block design and object assembly subtests), (3) freedom from distractibility (digit span and coding subtests).

The child's score for the Burt reading test was converted to a reading age. The number of correct associations for the learning task was noted for each of the three trials separately for the easy and hard associations. For the visual memory task $^{19}$ the number of objects recalled unaided, and those recalled with prompting and by recognition, were recorded. The visual memory for abstract design was scored according to the manual and a cumulative score for the three designs calculated. The Rutter
Teacher Behaviour Questionnaire was scored in the usual way, higher scores indicating more behavioural deviance.

Children treated for leukaemia compared with normal children. The mean score for each test completed by leukaemic children was compared with that completed by normal children using a series of $t$ tests (Table 1). Children treated for leukaemia had lower scores than normal children on all measures derived from the WISC-R and for reading ability. On the unstandardised measures of learning and memory, there was little difference between the groups in their ability to recall the familiar objects after a 10minute period. However, the normal children achieved higher scores on the test of memory for abstract designs. On the learning task the number of easy and hard associations correctly learned in the three trials was compared for both groups of children. Although there were no differences in the number of hard associations learned (mean associations learned by normal children $=2 \cdot 27$ and by leukaemic children $=2 \cdot 14$ ), normal children learned more easy associations (mean associations learned by normal children $=5.32$ and by leukaemic children $=4 \cdot 79, t=2 \cdot 29, \mathrm{P}<0 \cdot 03$ ).

Children treated for solid tumours compared with normal children. Mean scores on all tests for both groups of children were compared using a series of $t$ tests (Table 2). On one subtest of the WISC-Robject assembly - normal children scored higher than patients with solid tumours. There was no other difference between the groups.

\section{Effects of age at diagnosis.}

\section{Leukaemic children}

It was predicted that in children treated for leukaemia, those who had been diagnosed and given irradiation

Table 1 Mean scores obtained by normal children and those with leukaemia

\begin{tabular}{|c|c|c|c|}
\hline \multirow[t]{2}{*}{ Test } & \multicolumn{2}{|l|}{ Children } & \multirow[b]{2}{*}{$t$ test } \\
\hline & $\begin{array}{l}\text { With } \\
\text { leukaemia }\end{array}$ & Normal & \\
\hline $\begin{array}{l}\text { IQ } \\
\text { Full scale } \\
\text { Verbal scale } \\
\text { Performance scale }\end{array}$ & $\begin{array}{l}93 \cdot 83 \\
95 \cdot 88 \\
92 \cdot 83\end{array}$ & $\begin{array}{l}105 \cdot 75 \\
106 \cdot 78 \\
103 \cdot 13\end{array}$ & $\begin{array}{l}4 \cdot 27^{* *} \\
3 \cdot 83^{* *} \\
3 \cdot 13^{*}\end{array}$ \\
\hline $\begin{array}{l}\text { Kaufman factors } \\
\text { Verbal comprehension } \\
\text { Perceptual organisation } \\
\text { Freedom from distractibility }\end{array}$ & $\begin{array}{l}18 \cdot 65 \\
17 \cdot 53 \\
17 \cdot 63\end{array}$ & $\begin{array}{l}21 \cdot 50 \\
21 \cdot 45 \\
22 \cdot 00\end{array}$ & $\begin{array}{l}2 \cdot 61 * \\
3 \cdot 51^{* *} \\
5 \cdot 12^{* *}\end{array}$ \\
\hline $\begin{array}{l}\text { Reading age } \\
\text { Rutter score }(n=24)\end{array}$ & $\begin{array}{r}102 \cdot 15 \\
3 \cdot 33\end{array}$ & $\begin{array}{r}118 \cdot 76 \\
1 \cdot 33\end{array}$ & $\begin{array}{l}4 \cdot 84^{* *} \\
2 \cdot 91^{*}\end{array}$ \\
\hline
\end{tabular}


Table 2 Mean scores obtained by normal children and those with solid tumours

\begin{tabular}{|c|c|c|c|}
\hline \multirow[t]{2}{*}{ Test } & \multicolumn{2}{|l|}{ Children } & \multirow[b]{2}{*}{$t$ test } \\
\hline & $\begin{array}{l}\text { With } \\
\text { solid tumours }\end{array}$ & Normal & \\
\hline \multicolumn{4}{|l|}{ IQ } \\
\hline $\begin{array}{l}\text { Full scale } \\
\text { Verbal scale } \\
\text { Performance scale }\end{array}$ & $\begin{array}{r}101 \cdot 37 \\
105 \cdot 25 \\
96 \cdot 75\end{array}$ & $\begin{array}{l}106 \cdot 50 \\
106 \cdot 25 \\
105 \cdot 38\end{array}$ & $\begin{array}{l}-1 \cdot 07 \\
-0 \cdot 19 \\
-1 \cdot 57\end{array}$ \\
\hline \multicolumn{4}{|l|}{ Kaufman factors } \\
\hline $\begin{array}{l}\text { Verbal comprehension } \\
\text { Perceptual organisation } \\
\text { Freedom from distractibility }\end{array}$ & $\begin{array}{l}21 \cdot 06 \\
19 \cdot 63 \\
20 \cdot 82\end{array}$ & $\begin{array}{l}20 \cdot 75 \\
22 \cdot 25 \\
22 \cdot 44\end{array}$ & $\begin{array}{r}-1 \cdot 49 \\
\cdot 16 \\
-1 \cdot 50\end{array}$ \\
\hline $\begin{array}{l}\text { Reading age } \\
\quad \text { Rutter score }(n=10)\end{array}$ & $3 \cdot 30$ & $2 \cdot 80$ & 0.35 \\
\hline
\end{tabular}

when very young would be particularly at risk. To look at this, a difference score was calculated for each child between his own scores and those of his matched control. These difference scores were calculated on the basis of those made by the control, minus those made by the leukaemic child; thus a more positive score represented a greater deficit in relation to the normal. These scores were then correlated with the patient's age at diagnosis. If younger children were more at risk we would expect a significant negative correlation, and this was so (Table 3). As an alternative way of looking at these data, the group was divided into two, depending on whether they had been diagnosed before or after 5 years of age. As shown (Table 4), the younger group performed significantly less well than their controls but this was not so for the older group.

\section{Children with solid tumours}

The above correlations were repeated on the scores obtained by children treated for solid tumours and compared with normal controls. In no case did the correlation with age at diagnosis reach significance, either for the group as a whole, or for either gender considered separately.

Table 3 Effects of age at diagnosis: correlations with scores for children treated for leukaemia and solid tumours

\begin{tabular}{lll}
\hline & \multicolumn{2}{l}{ Children } \\
\cline { 2 - 2 } & With leukaemia & With solid tumours \\
\hline IQ & & \\
Full scale & $-0.43^{* *}$ & 0.05 \\
Verbal scale & -0.27 & 0.14 \\
Performance scale & $-0.42^{* *}$ & -0.04 \\
Kaufman factors & & \\
Verbal comprehension & -0.26 & 0.14 \\
Perceptual organisation & $-0.38^{*}$ & -0.06 \\
Freedom from distractibility & -0.10 & 0.06 \\
\hline
\end{tabular}

**P<0.006, *P<0.01.
Table $4 I Q$ scores of leukaemic and normal children depending on the age of diagnosis of the leukaemic child

\begin{tabular}{llllll}
\hline$I Q$ & $\begin{array}{l}\text { Leukaemic Controls } \\
\text { children } \\
\text { diagnosed } \\
<5 \text { years }\end{array}$ & $P$ & $\begin{array}{l}\text { Leukaemic Controls } \\
\text { children } \\
\text { diagnosed } \\
>5 \text { years }\end{array}$ \\
\hline Full scale & 95 & 111 & $4 \cdot 45^{*} 92$ & 98 \\
Verbal scale & 99 & 112 & $3 \cdot 9^{*}$ & 92 & 100 \\
Performance scale & 92 & 108 & $3 \cdot 6^{*}$ & 93 & 96 \\
\hline
\end{tabular}

${ }^{*} \mathrm{P}<0.05$

The child in school.

\section{Leukaemic children}

School reports were obtained for 24 pairs of the 40 children treated for leukaemia and their controls, and for 12 of the 16 pairs of children treated for solid tumours. Teachers were first asked to complete the Rutter Teacher Behaviour Questionnaire to assess the incidence of behavioural disturbance. The mean score obtained by the leukaemic children was higher than for normal children. Although this result suggests that the leukaemic children had a higher incidence of behavioural disorder than normal children, the scores of both groups were very low compared with those reported previously. ${ }^{20}$ This discrepancy may partly be accounted for by the higher age of the children in the study.

Teachers were also asked to rate the attendance of children according to one of 5 categories-very poor, poor, good, very good, or excellent. The attendance of most children was rated as good, very good, or excellent. None of the normal children was rated as having poor attendance, but 3 of 29 leukaemic children were so described. 11 of the leukaemic children had received, or were still receiving, remedial help compared with only 1 normal child.

\section{Children with solid tumours}

There were no differences in Rutter scores obtained by children in the two groups. One of the 12 children treated for a solid tumour still had a poor attendance record, but all other children were described as having good or excellent attendance records. Three had had remedial help at school.

\section{Discussion}

Previous work suggests that children suffering from chronic illness compare in intellectual ability with normal children, and our results for those treated for solid tumours are consistent with these findings. Despite the many factors that could limit or retard the intellectual growth of a child treated for a lifethreatening cancer, these data suggest that their abilities are unaffected. 
For leukaemic children however, there is a systematic bias in favour of normal peers across the range of skills measured in this study. This might be interpreted as indicative of some specific aspects of the illness or its treatment over and above the general handicapping influences of sickness during childhood. As the majority of these children had been treated by CNS irradiation of a similar dosage and with methotrexate, it is difficult to disentangle the mechanisms. Provided that the total dosage of irradiation is below the normally accepted tolerance level for the brain, it seems likely that it is the combined effect of CNS irradiation and chemotherapy that is responsible. This interpretation is consistent with previous findings. ${ }^{11}$

An alternative explanation may be that the accepted safe levels of irradiation are applicable to fully mature individuals, and are too high for young children. The finding of increased vulnerability among younger patients supports this hypothesis, and is also consistent with the work of Dobbing. ${ }^{21}$

Earlier studies suggested that after CNS irradiation, children are likely to show specific learning difficulties. Eiser and Lansdown, ${ }^{15}$ for example, noted that patients diagnosed before 5 years of age had greater difficulty with counting, memorising, and motor tasks, but that language skills were normal. Soni et al., ${ }^{12}$ found no real evidence of specific learning problems, but suggested that irradiation might damage the child's general learning capacity. The results of our study suggest that all aspects of the leukaemic child's learning skills and attainments, including language and reading, are below those of normal children. Leukaemic children had lower scores on all measures of IQ, as well as for memory of abstract designs and in the brief learning test. The results are consistent with previous work if it is assumed that in time the reduction in learning capacity noted by Soni et al. ${ }^{12}$ becomes noticeable across a range of skills. The length of time this group of children had been off treatment was much longer than for the group studied by Eiser and Lansdown. ${ }^{15}$ Further work is needed to clarify the relationship between the child's psychological recovery and the duration of the illness. These data must however, be considered in relation to the accumulating reports which attest to residual neurological, behavioural, and intellectual growth, and hormonal problems in children treated for leukaemia.

The author is grateful to $\mathrm{Dr} \mathbf{J}$ Chessells, Dr J Pritchard, and Professor P J Graham for their help.

The work was supported by a grant from the Medical Research Council, London.

\section{References}

1 Pless I B, Pinkerton P. Chronic childhood disorder. London: Kimpton, 1975.

2 Burton L, ed. Care of the child facing death. London: Routledge \& Kegan Paul, 1974.

3 Gayton W F, Friedman S B. Psychosocial aspects of cystic fibrosis. Am J Dis Child 1973; 126: 856-9.

4 Ack M, Miller I, Weil W B, Jr. Intelligence of children with diabetes mellitus. Pediatrics $1961 ; 28$ : 764-70.

5 Olch D. Effects of hemophilia upon intellectual growth and academic achievement. J Genet Psychol 1971 ; 119: 63-74.

6 Allen G H. Aspirations and expectations of physically impaired high school seniors. Personnel and Guidance Journal 1967; 47: 59-60.

7 Barsch R H. The parents of the handicapped child. Springfield, Illinois: Thomas, 1968.

8 Hewitt S, Newson J, Newson E. The family and the handicapped child. Chicago: Aldine, 1970.

9 Peylan-Ramu N, Poplack D G, Pizzo P A, Adornato B T, Di Chiro G. Abnormal CT scans of the brain in asymptomatic children with acute lymphocytic leukemia after prophylactic treatment of the central nervous system with radiation and intrathecal chemotherapy. $N$ Engl J Med 1978; 298: 815-8.

10 McIntosh S, Klatskin E H, O'Brien R T, et al. Chronic neurologic disturbance in childhood leukemia. Cancer $1976 ; 37$ : 853-7.

11 Price R A, Jamieson A J. The central nervous system in childhood leukemia. II. Subacute leukoencephalopathy. Cancer 1975; 35: 306-18.

12 Soni S S, Marten G W, Pitner S E, Duenas D A, Powazek $M$. Effects of central nervous system irradiation on neurpsychologic functioning of children with acute lymphoblastic leukemia. $N$ Engl J Med 1975; 293: 113-8.

13 Verzosa M S, Aur R J A, Simone J V, Hustu O H, Pinkel D P. Five years after central nervous system irradiation of children with leukemia. Int J Radiat Oncol Biol Phys 1976; 1 : 209-15.

14 Meadows P T, Evans A E. Effects of chemotherapy on the central nervous system. A study of parental methotrexate in long-term survivors of leukemia and lymphoma in childhood. Cancer 1976; 37: 1079-85.

15 Eiser C, Lansdown R. Retrospective study of intellectual development in children treated for acute lymphoblastic leukaemia. Arch Dis Child 1977; 52: 525-9.

16 Quinton D, Rutter M. Early hospital admissions and later disturbances of behaviour. Dev Med Child Neurol $1976 ; 18$ : 447-59.

17 Kaufman A S. Factor analysis of the WISC-R at 11 age levels between $6 \frac{1}{2}$ and $16 \frac{1}{2}$ years. J Consult Clin Psychol $1975 ; 43$ : $135-47$.

18 Wechsler D. A standardized memory scale for clinical use. New York: The Psychological Corporation, 1973.

19 Williams $M$. The measurement of memory in clinical practice. Br J Soc Clin Psychol 1968; 7: 19-34.

20 Stevenson J E, Hawcroft J, Lobascher M, Smith I, Wolff O H, Graham P J. Behavioural deviance in children with early treated phenylketonuria. Arch Dis Child 1979; 54: 14-8.

21 Dobbing J. Vulnerable periods in the developing brain. In: Davison A M, Dobbing J, eds. Applied neurochemistry. Oxford: Blackwell, 1968; 287.

Correspondence to Dr Christine Eiser, Department of Psychology, Washington-Singer Laboratory, University of Exeter, Exeter, Devon.

Received 15 May 1979 